\title{
Analysis of Farmers' Cognition, Purchase Intention and Agricultural Insurance Development Status - Taking Yunnan Province as an Example
}

\author{
Yu Song ${ }^{1}$ Renbo Jiang ${ }^{1}$ Xin Peng ${ }^{1}$ Yerong $\mathrm{Li}^{1}{ }^{1 *}$ \\ ${ }^{1}$ College of Economics and Management, Yunnan Agricultural University, Kunming, Yunnan 650201, China \\ *Corresponding author. Email: leeyr1965@163.com
}

\begin{abstract}
Agricultural insurance is a management method that effectively responds to agricultural risks and an effective way to protect agricultural production activities. At present, Yunnan Province has frequent natural disasters and severe economic losses, restricting the development of agriculture there. Farmers have limitations in their perception of agricultural insurance, affecting their willingness to buy and participate in agriculture as well as their desire to achieve stable income and increase and create income. Therefore, it is necessary to improve farmers' purchasing intention and participation behavior, understand farmers' purchasing needs and analyze influencing factors, so that agricultural insurance can play a key role. Based on the agriculture conditions of Yunnan Province, the development status of agricultural insurance in Yunnan Province, and farmers' cognitive behaviors, this paper analyzes from three aspects to find the factors affecting the development of agricultural insurance and the main reasons that hinder farmers' purchase intention, trying to use the thought of economics to analyze and explain their behavior, and putting forward feasible strategies to improve the development model of agricultural insurance in Yunnan Province.
\end{abstract}

Keywords: Agricultural insurance, Cognitive behavior, Purchase intention, Yunnan Province, Farmers.

\section{INTRODUCTION}

Since 2004, the government has issued the "No. 1 Central Document" for 17 consecutive years, emphasizing that the "issues relating to agriculture, rural areas, and rural people" have a "top priority" status against the background of this special era. In 2020 , the rural areas simultaneously realize the completion of a a moderately prosperous society in all respects, and the development of "agriculture, rural areas, and rural residents" has made historic achievements. 2021 opens a new chapter in the "14th Five-Year Plan" period, and the most important thing for national prosperity and national rejuvenation is still the vast rural areas. The No. 1 Central Document in 2021 specifically emphasizes the "guarantee of priority development input in agricultural and rural areas", and points out the necessity to deepen rural financial reform, establish and improve the agricultural reinsurance system, and play the important role of "insurance + futures" in serving the development of rural industries [1]. It can be seen that agricultural insurance is an important guarantee for the priority development of agricultural and rural areas, and the government attaches great importance to and actively promotes the development of agricultural insurance.

In terms of national policies and guidelines, agricultural insurance is an effective management method to deal with agricultural risks, and it is also an important part of the rural financial system. It is of great significance to the development of China's rural economy and the stability and prosperity of the society. Agricultural insurance is playing an increasingly important role in ensuring food security, promoting agricultural modernization, increasing farmers' income, helping the country's macroeconomic adjustments, stabilizing rural society, and serving the transformation of rural economic development patterns. In addition, agricultural insurance has also become a major component of China's policy to support farmers. 
For the government, the popularization and promotion of agricultural insurance is an imperative trend and goal. The popularization of insurance is one of the best ways to protect farmers' income and rights and interests.

From the perspective of the research area, Yunnan is a major agricultural province in China and agriculture is one of the pillar industries of Yunnan Province. According to the current situation, Yunnan's natural disasters have the characteristics of high frequency, wide distribution and numerous varieties, which are also one of the main factors restricting the development of agriculture in Yunnan Province, seriously affecting farmers' demand for stable income and increasing and creating income. Due to the dispersibility and fragility of the agricultural economy, the development of agriculture is still restricted. Because of its uncontrollability, the risk and pressure on agricultural production is still great. As far as farmers are concerned, their understanding of agricultural insurance has limitations such as incompleteness and inadequacy, restricting farmers' willingness and behavior to purchase agricultural insurance. Therefore, it is necessary to give play to the important role of agricultural insurance in risk spreading and income guarantee, improve farmers' purchasing intention and participation behavior, understand farmers' purchasing needs and analyze influencing factors, so that agricultural insurance can play a key role. This paper starts with the analysis of the status quo of agricultural insurance development in Yunnan Province and the perspective of farmers' cognitive behaviors, and finds the factors affecting the development of agricultural insurance and the main reasons that hinder farmers' purchase intention, trying to use the thought of economics to analyze and explain their behavior, and putting forward feasible strategies to improve the development model of agricultural insurance in Yunnan Province.

\section{THE BASIS AND IDEAS OF INVESTIGATION AND RESEARCH}

When it comes to insurance, the concept that has to be emphasized is "contract", and agricultural insurance is a manifestation of contract. From the perspective of contract theory, the conclusion of the contract is a kind of Pareto improvement. The interests of at least one party in a contractual transaction can be improved. It is precisely because of the emergence of the contract system that people of the same and different nationalities and different religious beliefs and cultural backgrounds can conduct transactions across time and place [2]. From the perspective of the function of the contract, the generation of the contract can enable the transaction of future events to be realized, and the way of the realization can only be executed by a contract with a pre-commitment such as insurance. From the perspective of contract, the problems of information asymmetry, adverse selection, and moral hazard are also derived, because factors such as the difference and asymmetry of information sources and the difference of human cognition have led to the above problems. Therefore, the cognitive difference of farmers is a significant factor in the purchase of agricultural insurance, and it is worthy of in-depth study.

This paper is based on the neoinstitutional economics as the basic idea of the research. In addition to the contract theory mentioned above, it also includes human cognition and ideology, as well as the path dependence theory generated under the social environment (including culture, habits, social system, etc.). And under the restriction of ideology, people think about problems according to the established path, and produce dependent thoughts, and it is difficult for them to jump out of fixed thoughts and behavior patterns. Therefore, farmers' cognitive behaviors and thinking patterns, as well as the root causes of these problems, have also had a profound impact on their behavior in purchasing and cognizing agricultural insurance.

The development of Yunnan Province's provincial conditions and agricultural conditions is relatively more complex and diverse. This article hopes to combine the actual questionnaire surveys and interviews with rural households through the analysis of Yunnan's provincial conditions and insurance conditions, to be able to understand objectively the analysis of objective factors that restrict the development of agricultural insurance in Yunnan Province and affect farmers' willingness to purchase, and be capable of finding a solution. At the same time, under the influence of the inherent social environment and consciousness, it is necessary to find a development model suitable for local agricultural insurance, and at the same time, it should be closely integrated with the national policy, letting agricultural insurance play its due role in consolidating the effect of poverty alleviation and the effective connection of rural revitalization. 
The article analyzes from three angles, including the situation of Yunnan Province, the analysis of the current situation of insurance in
Yunnan Province, and the analysis of farmers' understanding and purchase situation, as shown in the following "Figure 1":

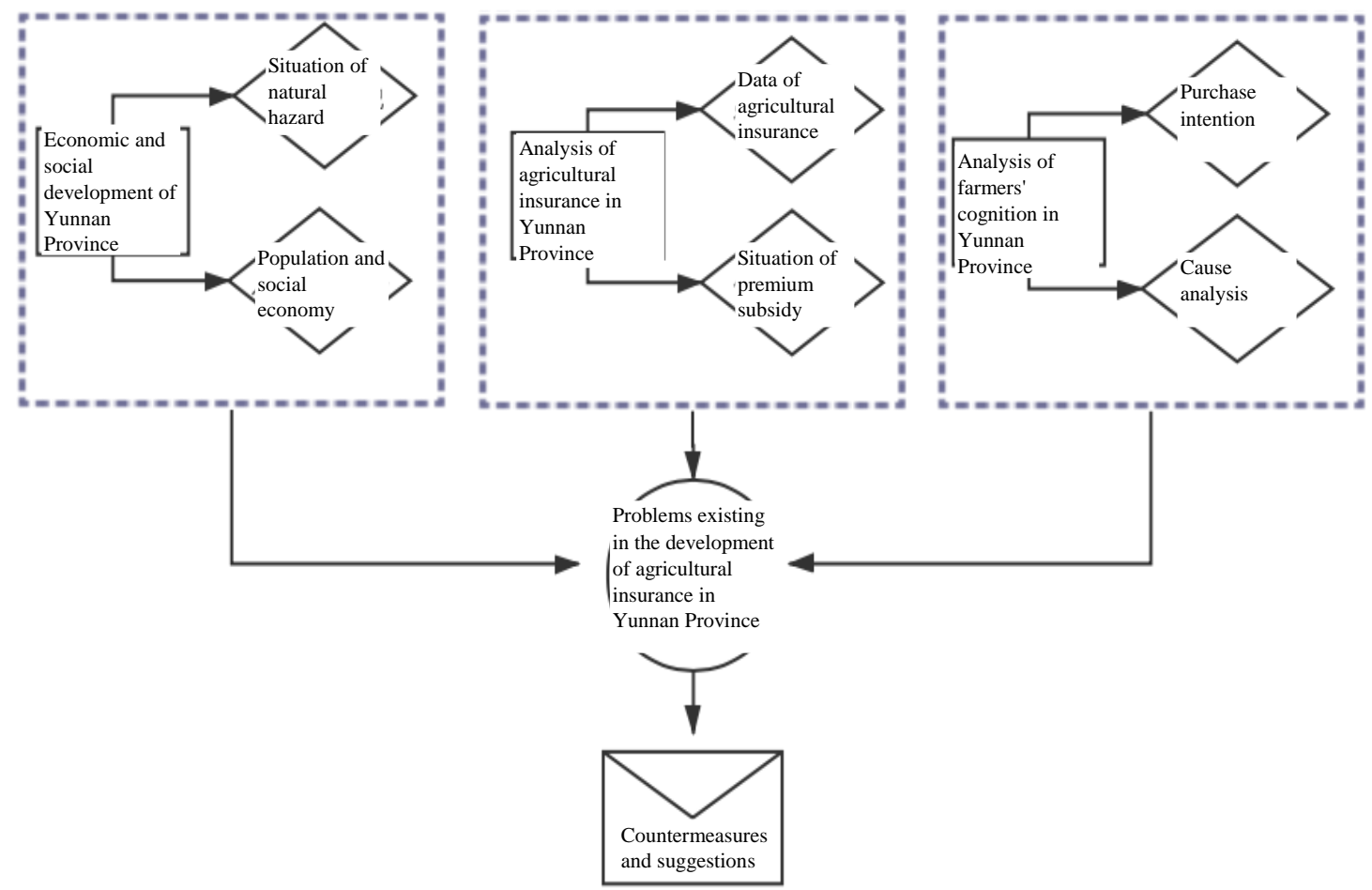

Figure 1 Research ideas.

\section{THE ECONOMIC AND SOCIAL DEVELOPMENT OF YUNNAN PROVINCE}

\subsection{Climate Types and Natural Disasters in Yunnan Province}

Yunnan Province is located in the southwestern border of China. Yunnan belongs to the mountainous plateau terrain with the mountainous area of $33.11 \mathrm{~km}^{2}$, accounting for $84 \%$ of the province's total land area. Its terrain is higher in the northwest and lower in the southeast, descending stepwise from north to south. The province's altitude difference is huge, and the altitude difference exceeds 6,000 meters. The threedimensional climate features are remarkable and there are many types. The climate category has a clear relationship with altitude and latitude. At the same time, there are three zones of climate in the province: frigid zone, temperate zone, and tropical (subtropical) zone. ("Figure 2") In Yunnan, there is a saying: One mountain at four seasons, different weather within a few miles. The scene there has its own characteristics. 


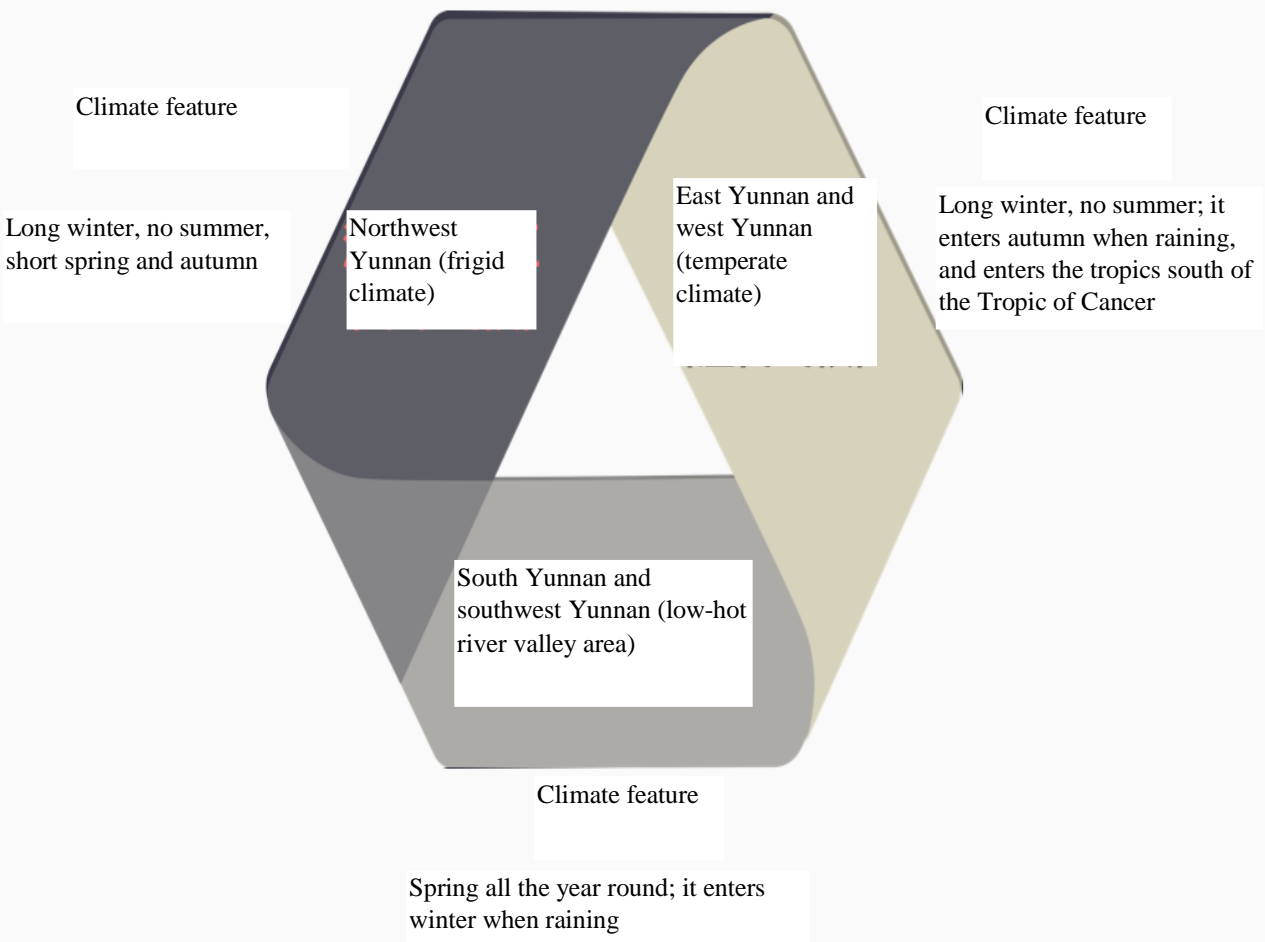

Figure 2 Climate categories and characteristics of Yunnan Province.

Because of its diversified climatic characteristics, more mountains and less flat land, the frequency of natural disasters in Yunnan is also relatively high, which has had an important impact on the economic and social development of Yunnan's rural areas, and also highlighted the

importance of agricultural insurance to guarantee agricultural production. After a brief summary of natural disasters, the occurrence of natural disasters in Yunnan Province in recent years is shown in the following "Table 1":

Table 1. Lose from natural calamity in Yunnan Province from 2014 to 2018

\begin{tabular}{|c|c|c|c|c|c|c|c|c|c|}
\hline Year & $\begin{array}{l}\text { Total damag } \\
\text { area } \\
\text { (thousand } \\
\text { hectares) }\end{array}$ & Drought & \begin{tabular}{|l|} 
Flood, \\
landslide, \\
mudslide and \\
typhoon
\end{tabular} & Hailstorm & $\begin{array}{l}\text { Chilling } \\
\text { damage and } \\
\text { snow disaster }\end{array}$ & $\begin{array}{l}\text { Affected } \\
\text { population } \\
\text { (person) }\end{array}$ & $\begin{array}{l}\text { Economic } \\
\text { losses } \\
(100 \\
\text { yuan })\end{array}$ & \begin{tabular}{l|l} 
ic & $\begin{array}{l}\text { National } \\
\text { ranking }\end{array}$ \\
million & economic \\
& losses
\end{tabular} & of \\
\hline 2014 & 882.0 & 332.0 & 282.7 & 157.1 & 74.5 & 1414.8 & 444.2 & 1 & \\
\hline 2015 & 1028.3 & 514.9 & 231.6 & 112 & 169.7 & 1279.2 & 141.9 & 5 & \\
\hline 2016 & 868.5 & 47.7 & 244.9 & 158.1 & 417.8 & 1168.7 & 141.0 & 11 & \\
\hline 2017 & 406.6 & 102.0 & 226.5 & 65.4 & 12.7 & 629.0 & 76.6 & 14 & \\
\hline 2018 & 274.8 & & 171.1 & 33.5 & 70.2 & 480.2 & 162.9 & 5 & \\
\hline
\end{tabular}

At the same time, it has also been compared with the national natural disaster situation. As shown in the table, natural disasters in Yunnan Province are more frequent and economic losses are more serious, which are also in a more prominent position in the country. This shows that natural disasters should not be underestimated for hindering the development of the agricultural economy in Yunnan Province. 


\subsection{Population, Society and General Situation of Yunnan Province}

There are 16 states (cities) in Yunnan Province. As of the end of 2018, the total population of Yunnan Province was 48.295 million, a net increase of 290,000 people compared with the previous year,

Table 2. The disposable income of rural residents in Yunnan Province from 2014 to 2018

\begin{tabular}{|l|l|l|l|l|l|l|}
\hline Year & 2014 & 2015 & 2016 & 2017 & 2018 & $\begin{array}{l}\text { Difference with national comparison } \\
(2018)\end{array}$ \\
\hline $\begin{array}{l}\text { The } \\
\text { province }\end{array}$ & whole 7456 & 8242 & 9020 & 9862 & 10768 & -3849 \\
\hline $\begin{array}{l}\text { The whole } \\
\text { country }\end{array}$ & 10489 & 11421 & 12363 & 14617 & \\
\hline
\end{tabular}

The disposable income of rural residents in Yunnan Province has shown a good growth trend, but compared with the national average data, there is still a large gap, being lower than the national average. On the whole, the disposable income of rural residents in Yunnan Province is low. and the natural population growth rate was $6.87 \%$, an increase of $0.02 \%$ from the previous year. At the end of 2018, the urbanization rate of Yunnan Province reached $47.81 \%$, an increase of $1.12 \%$ over the previous year. The disposable income of rural residents is as follows ("Table 2")

In the past ten years, the total output value of agriculture, forestry, animal husbandry and fishery

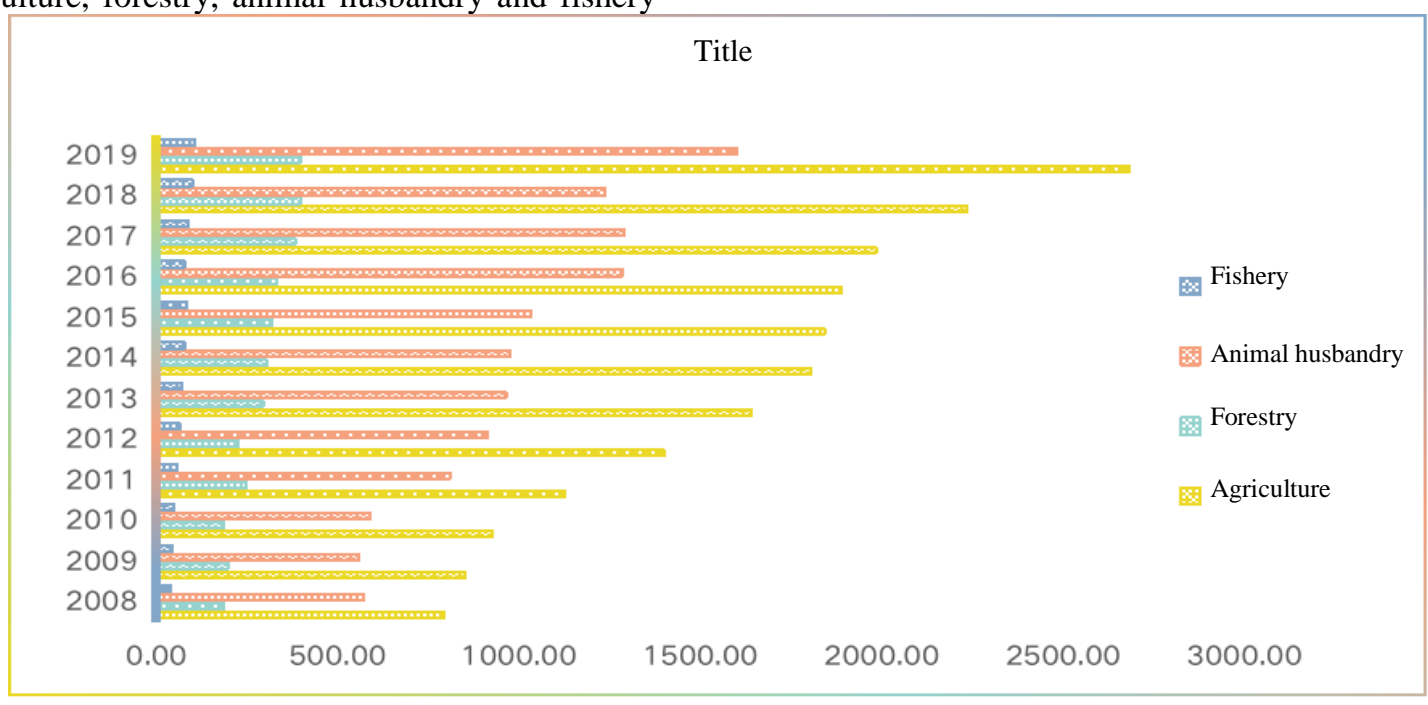

Figure 3 Statistics of the growth of agricultural output value in Yunnan Province from 2008 to 2019.

\section{DEVELOPMENT OF YUNNAN AGRICULTURAL INSURANCE}

\subsection{Climate Types and Natural Disasters in Yunnan Province}

In the past ten years, the agricultural insurance premium income of Yunnan Province has generally in Yunnan Province has been showing a steady growth trend, as shown in "Figure 3". The good growth trend reflects the good development momentum of agriculture in Yunnan Province and has laid a solid foundation for the development of agricultural insurance in Yunnan Province. 


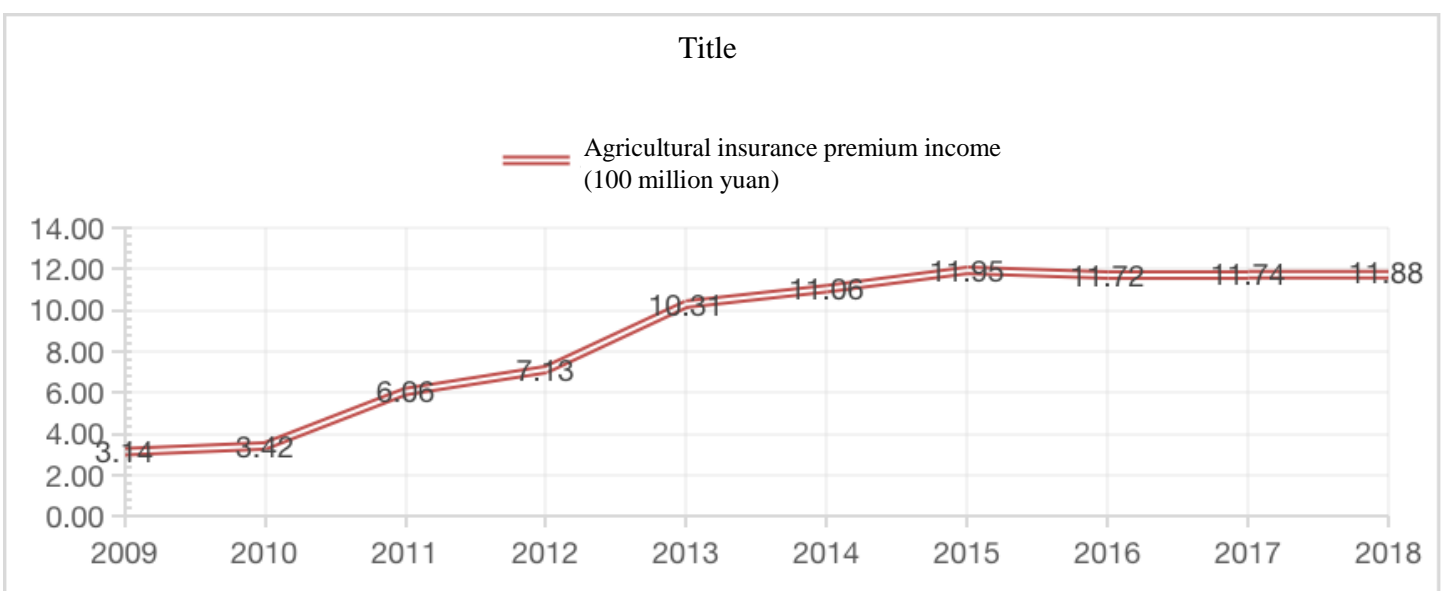

Figure 4 Statistics of agricultural insurance premium income in Yunnan Province in recent ten years.

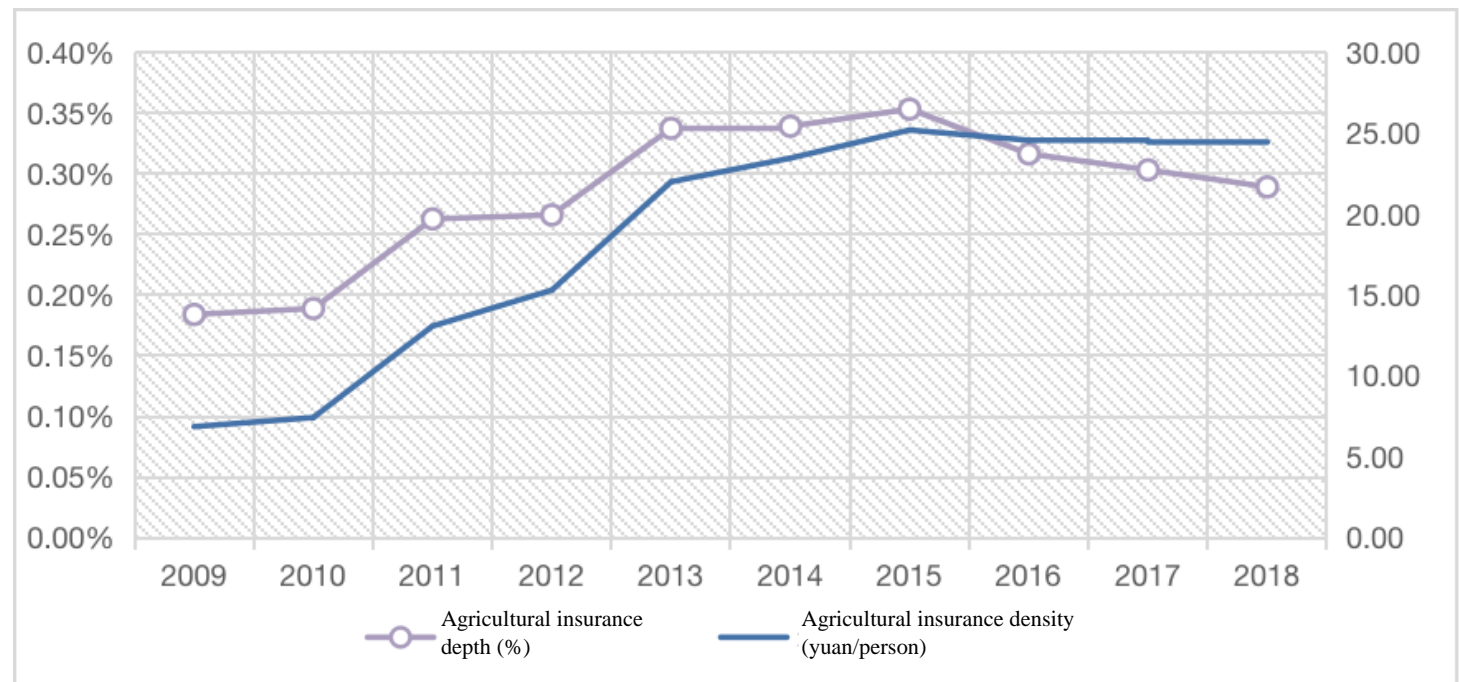

Figure 5 Statistics of agricultural insurance density and depth of agricultural insurance in Yunnan Province.

It is difficult to objectively reflect the development of Yunnan agricultural insurance through the analysis of premium income alone. Therefore, from the analysis of the three data analysis of the density and depth of agricultural insurance, the premium income, the density and depth of insurance have achieved a rapid growth trend in 2018 compared with 2009. 2015 was a peak period of development, after which the growth rate has slowed down. Combined with the natural disaster situation ("Table 3"), Yunnan Province suffered severe natural disasters in 2014, and its economic loss reached the first place in the whole country. A guess can be made: In the case of severe natural disaster losses, agricultural producers have realized the importance of agricultural insurance, so in 2015, insurance premium income has achieved a substantial increase. (see "Figure 6") 


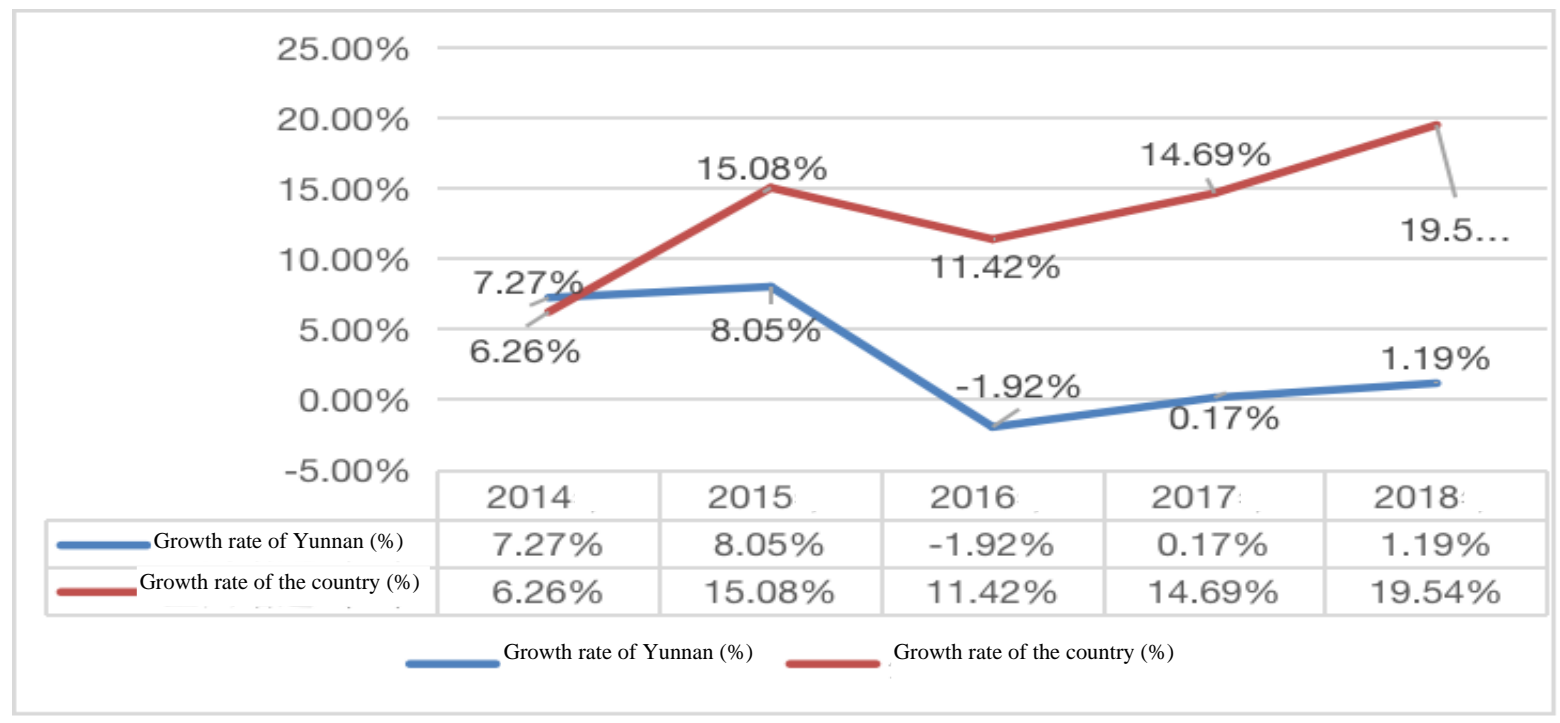

Figure 6 Statistics of the comparison of the growth rate of agricultural insurance between Yunnan Province and the whole country.

a Data source: The data are sorted out from "Yunnan Statistical Yearbook", "China Insurance Yearbook" and "China Statistical Yearbook"

Table 3. Statistical table of the comparison of agricultural insurance in Yunnan Province and the whole country in the past five years

\begin{tabular}{|c|c|c|}
\hline \multirow{2}{*}{ Year } & \multicolumn{2}{|c|}{$\begin{array}{l}\text { Analysis of the comparative situation of agricultural insurance guarantee } \\
\text { degree }\end{array}$} \\
\hline & Situation in Yunnan Province & Situation in the whole country \\
\hline 2014 & $0.34 \%$ & $0.33 \%$ \\
\hline 2015 & $0.35 \%$ & $0.37 \%$ \\
\hline 2016 & $0.32 \%$ & $0.39 \%$ \\
\hline 2017 & $0.30 \%$ & $0.44 \%$ \\
\hline 2018 & $0.29 \%$ & $0.50 \%$ \\
\hline
\end{tabular}

Compared with the whole country, the agricultural guarantee degree and insurance density of Yunnan Province are relatively behind the national level in terms of development. The guarantee degree has been hovering and maintaining a state of relatively little difference, which also reflects the incomplete coverage and insufficient coverage of agricultural insurance. In terms of insurance density, Yunnan Province is also far behind the national average, but this also has a certain relationship with the urbanization rate. The average urbanization rate of Yunnan Province is relatively low compared with that of the whole country, so the insurance density is also far behind the national level. In terms of growth rate, agricultural insurance in Yunnan Province has shown a declining and stagnant state. Compared with the rising trend in the whole country, the growth rate of insurance premium is far behind, indicating that there is still a lot of room for development of agricultural insurance in Yunnan Province. 


\section{ANALYSIS OF FARMERS' COGNITION AND PURCHASE INTENTION OF AGRICULTURAL INSURANCE IN YUNNAN PROVINCE}

This paper selects more than 400 farmer households in Yunnan Province to conduct a questionnaire survey, and takes a total of 430 valid questionnaires back, and all 16 states and cities are involved. Regarding the purchase and cognition of agricultural insurance by farmers, this paper selects several key survey data for analysis.

\subsection{Analysis of the Basic Situation of the Surveyed Farmers}

\subsubsection{Gender Analysis}

In the survey, there are 270 men $(62.97 \%)$ and 160 women $(37.21 \%)$ of the rural households

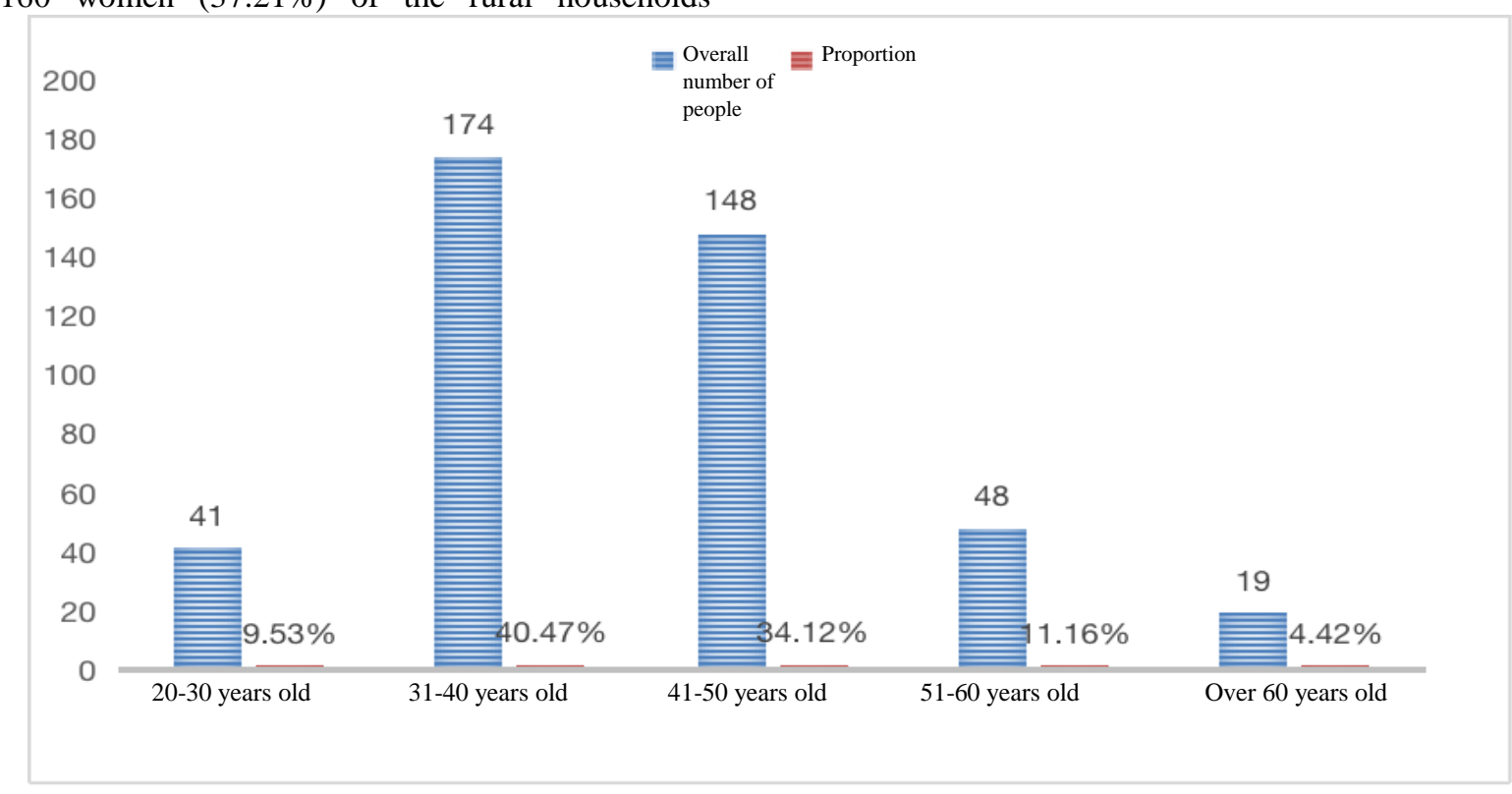

Figure 7 Statistical table of age distribution of surveyed households.

\subsubsection{Educational Level Analysis}

According to the analysis of the survey results, the main educational level of the interviewees is junior high school $(67.67 \%)$, followed by primary school (9.3\%). After consulting the "China Statistical Yearbook" and analyzing the data of a sample of the educated population over 6 years old surveyed. What is consistent with the expected situation is that the rural society still has the social situation where men are "masters of the house". However, according to the actual survey situation, the buying intention of men and the buying intention of women are almost the same, accounting for $58 \%$ and $57 \%$ of the total survey data respectively. This shows that gender is not the main factor affecting purchase intention.

\subsubsection{Age Analysis}

This study divides the interviewed farmers into 5 age groups: $20-30$ years old $(9.53 \%), 31-40$ years old $(40.47 \%), 41-50$ years old $(34.12 \%), 51-60$ years old $(11.16 \%)$, and over 60 years old $(4.42 \%)$. It can be seen that most of the interviewed age groups are in the age group of 31-40 years old and 41-50 years old. ("Figure 7")

Statistics of the age and proportion of rural households surveyed and studied in Yunnan Province. 


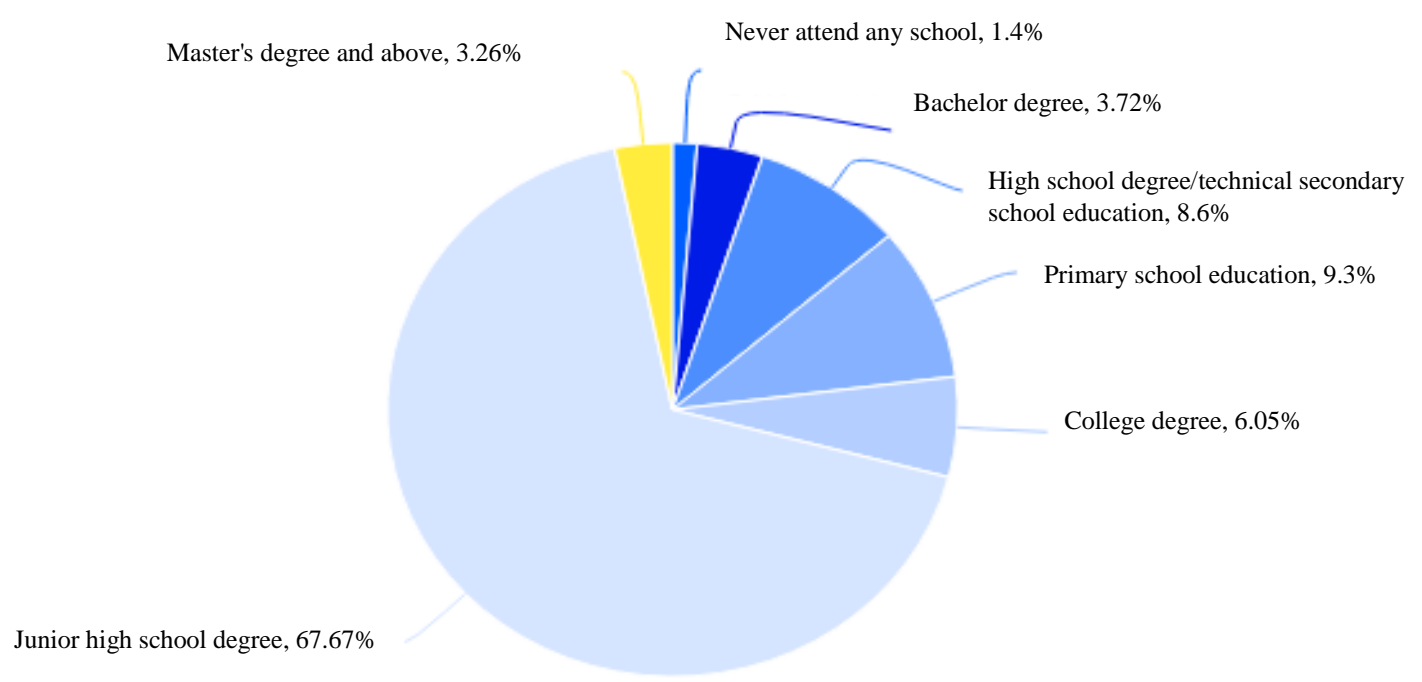

Figure 8 Statistics of the age and proportion of rural households surveyed and studied in Yunnan Province.

\subsubsection{Annual Household Income Analysis}

This study divides the surveyed farmers' income into ten ranges, ranging from less than 10,000 yuan to more than 500,000 yuan. After data analysis, the high probability that the annual household income of farmers is between 10,000 to 20,000 yuan $(22.79 \%)$ and 20,000 to 40,000 yuan $(20.70 \%)$, followed by low-income groups of less than 10,000 yuan (14.42\%). Farmers with 40,000-60,000 yuan (11.63\%) and 80,000-100,000 yuan (11.63\%) also account for a certain proportion respectively. On the whole, there are still a large number of lowincome groups, and there is a trend of gradual differentiation.

\subsubsection{Natural Hazard Analysis}

Among the 430 questionnaires issued by the survey, $313(72.79 \%)$ farmers say that they suffered natural disasters of varying degrees in the past five years, and only $27.21 \%$ of farmers say that they didn't suffer natural disasters. Based on the situation in "Table 3", the natural disasters in Yunnan Province are relatively serious, reflecting the importance of agricultural insurance in ensuring sustainable agricultural production from the side.

\subsection{Analysis on the Intention of Surveyed Farmers to Purchase Agricultural Insurance}

\subsubsection{Analysis of the Proportion of Agricultural Insurance Purchase}

Out of the 430 valid questionnaires, only onefifth, namely, 94 (21.68\%) farmers, has purchased agricultural insurance. The remaining four-fifths, namely, $336(78.14 \%)$ farmers, have not purchased agricultural insurance. ("Figure 9")

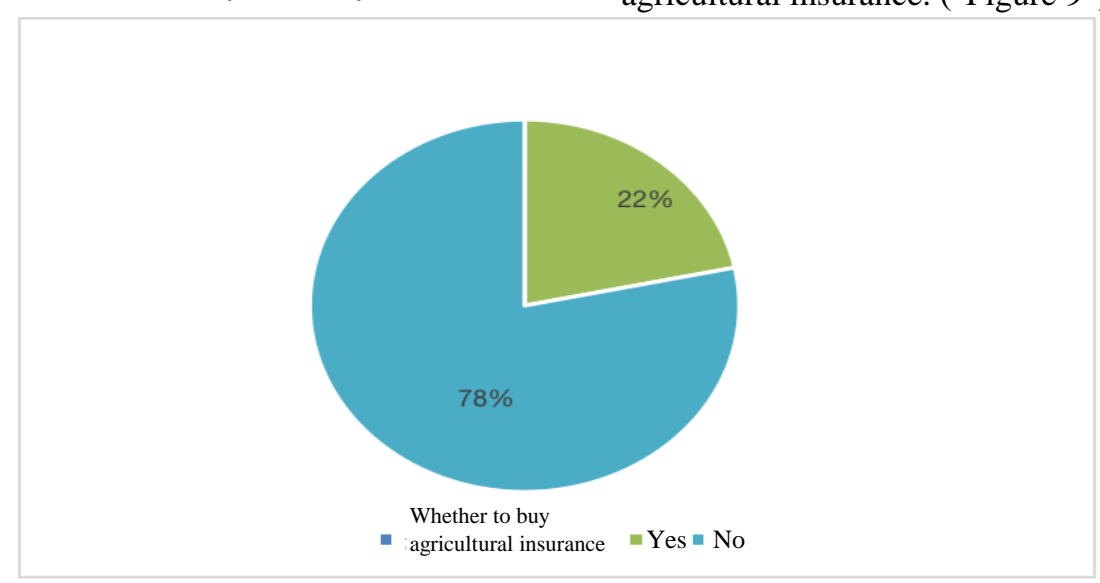

Figure 9 Statistics of farmers' intention to purchase agricultural insurance in Yunnan Province. 


\subsubsection{Analysis of Intention to Purchase Agricultural Insurance}

When asked whether they would like to buy agricultural insurance, $245 \quad(56.98 \%)$ farmers indicate that they would like to buy agricultural insurance, and $185(43.02 \%)$ respondents are unwilling to buy agricultural insurance. Only more than half of the people have the intention of purchase, and the situation is not very optimistic. ("Figure 10") For farmers who are unwilling to buy the agricultural insurance, further reason analysis will be carried out later.

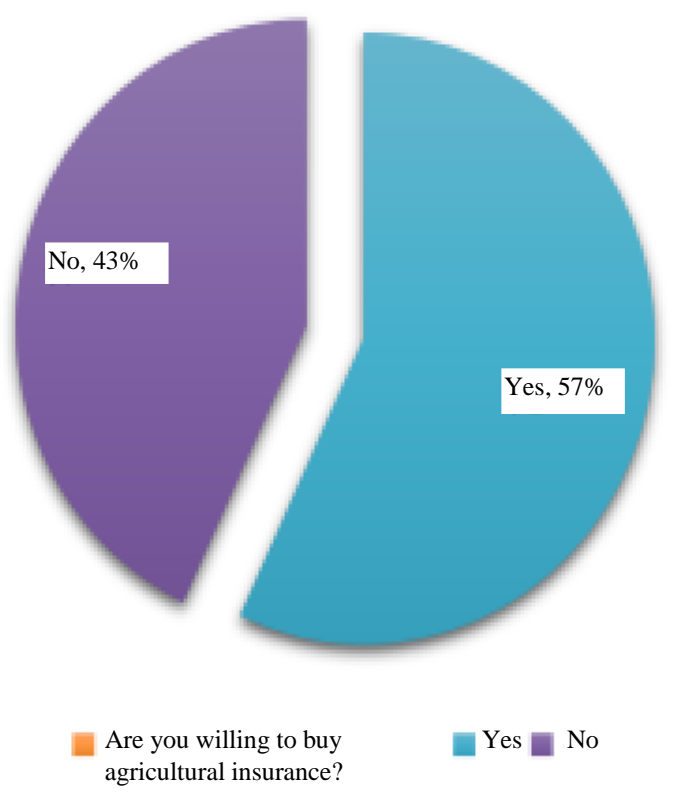

Figure $10 \quad$ Statistics of farmers' intention to purchase agricultural insurance in Yunnan Province.

For farmers who are unwilling to buy the agricultural insurance, it further conducts in-depth inquiry analysis to understand the reasons for unwillingness to purchase. The questionnaire classifies and investigates according to the five dimensions of solution of risks, cost, government subsidies, risk self-assessment, and insurance credibility. ("Figure 11")

From the perspective of the option "very consistent", most farmers who are unwilling to purchase agricultural insurance have an attitude of "don't understand or believe in agricultural insurance". The analysis shows that this option has a relatively strong consistency. Among the "least inconsistent" options, farmers unanimously choose the option "it doesn't matter because of the low cost". For most farmers, the input cost (money, labor, time) of agricultural production is a relatively large input cost, but it is often accompanied by relatively high risks (meteorological disasters, etc.). From the perspective of a rational-economic man, as a rational-economic man, it's impossible for farmers to fail to understand the cost of their investment in agricultural production. If the production activities and income sources of agricultural producers are relatively single, the possibility of taking risks will be further increased. 


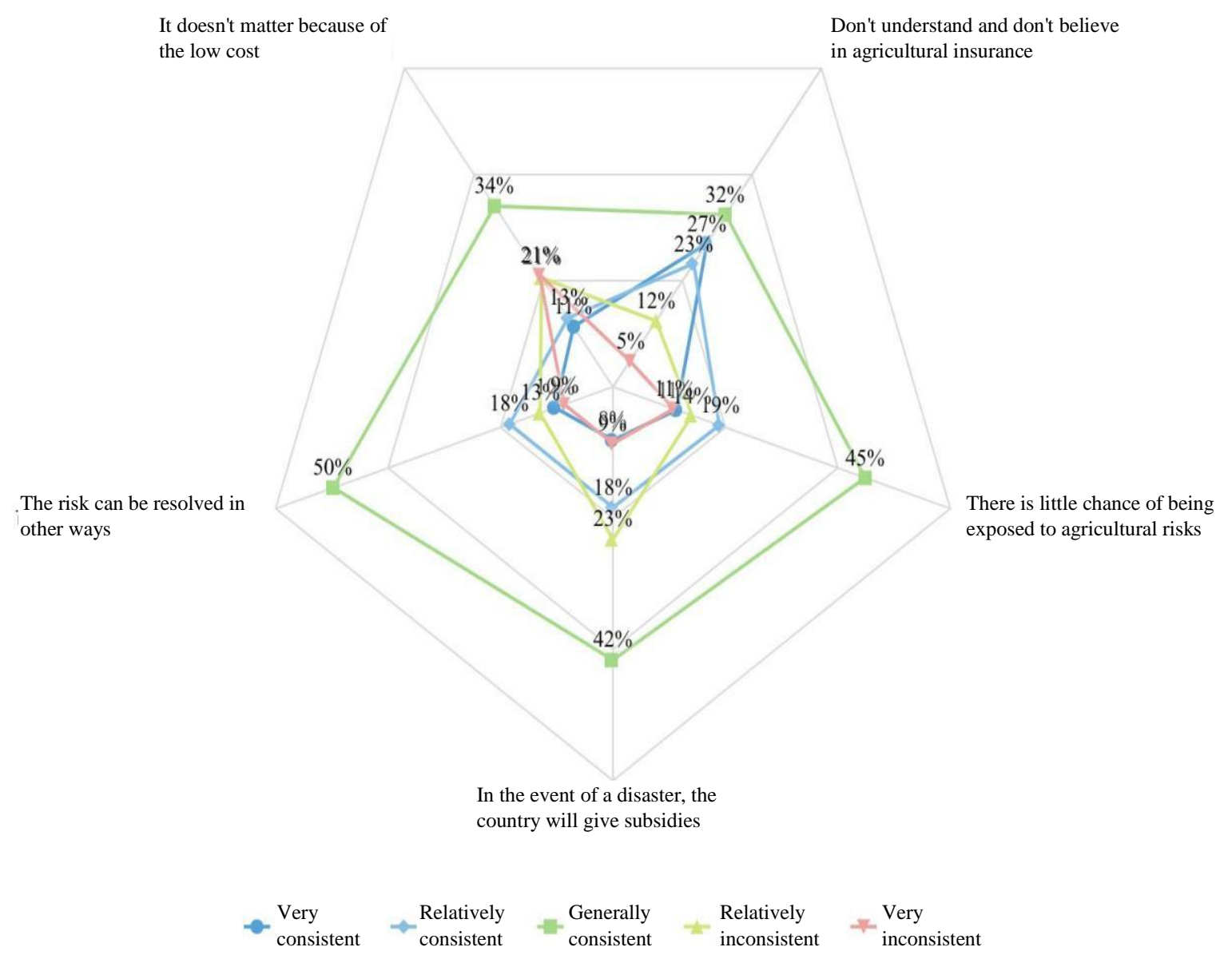

Figure 11 Analysis of reasons why interviewed farmers are unwilling to purchase agricultural insurance.

For farmers who are willing to purchase but have not purchased agricultural insurance, this study analyzes from seven aspects, including the degree of satisfaction of the types of agricultural insurance provided, the degree of agricultural insurance coverage, agricultural risk assessment, business model, loss tolerance, insurance premium tolerance, the degree of satisfaction with the amount of compensation. And questions are set up accordingly.

From the perspective of "very consistent", "there is no such service around" is a consistent choice for farmers.

This reflects the insufficient coverage of agricultural insurance from the side. From the perspective of "relatively inconsistent" and "very inconsistent", "diversified operations" and "there is little chance of being exposed to agricultural risks" are the preferences of choice, reflecting the simplification of agricultural production and the fact that farmers have a relatively high degree of worrying about agricultural risks from the side.. ("Figure 12") 


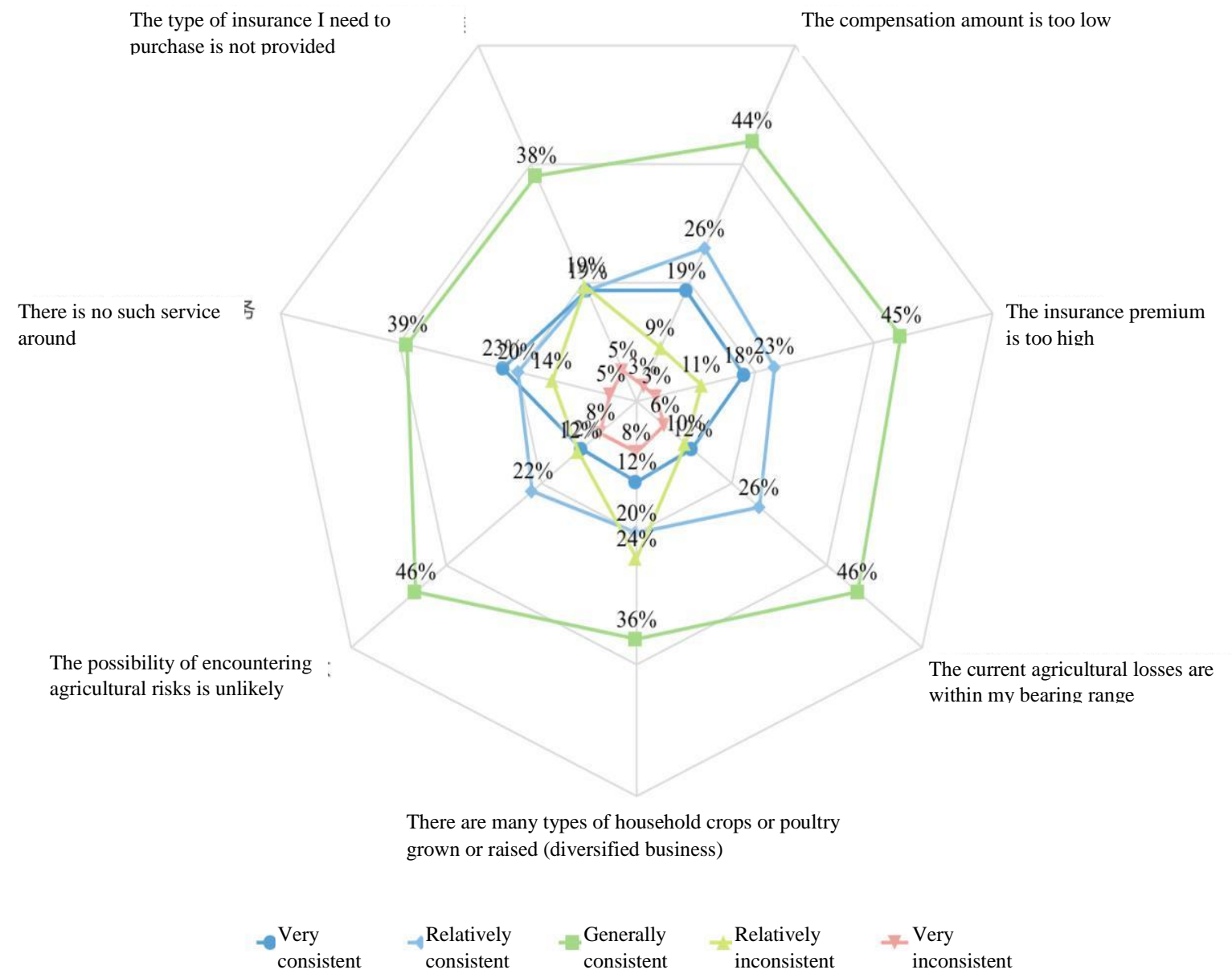

Figure 12 Analysis of the reasons why the interviewed farmers have not yet purchased agricultural insurance.

\subsubsection{Comparative Analysis of Annual Household Income and Purchase Intention}

Comparing the annual household income in ten ranges, it is found that the willingness to buy agricultural insurance is proportional to the income of the household. The high family income also means that farmers bear more agricultural risks than low-income groups, and they are also more active in protecting their own property income.. ("Figure 13") 


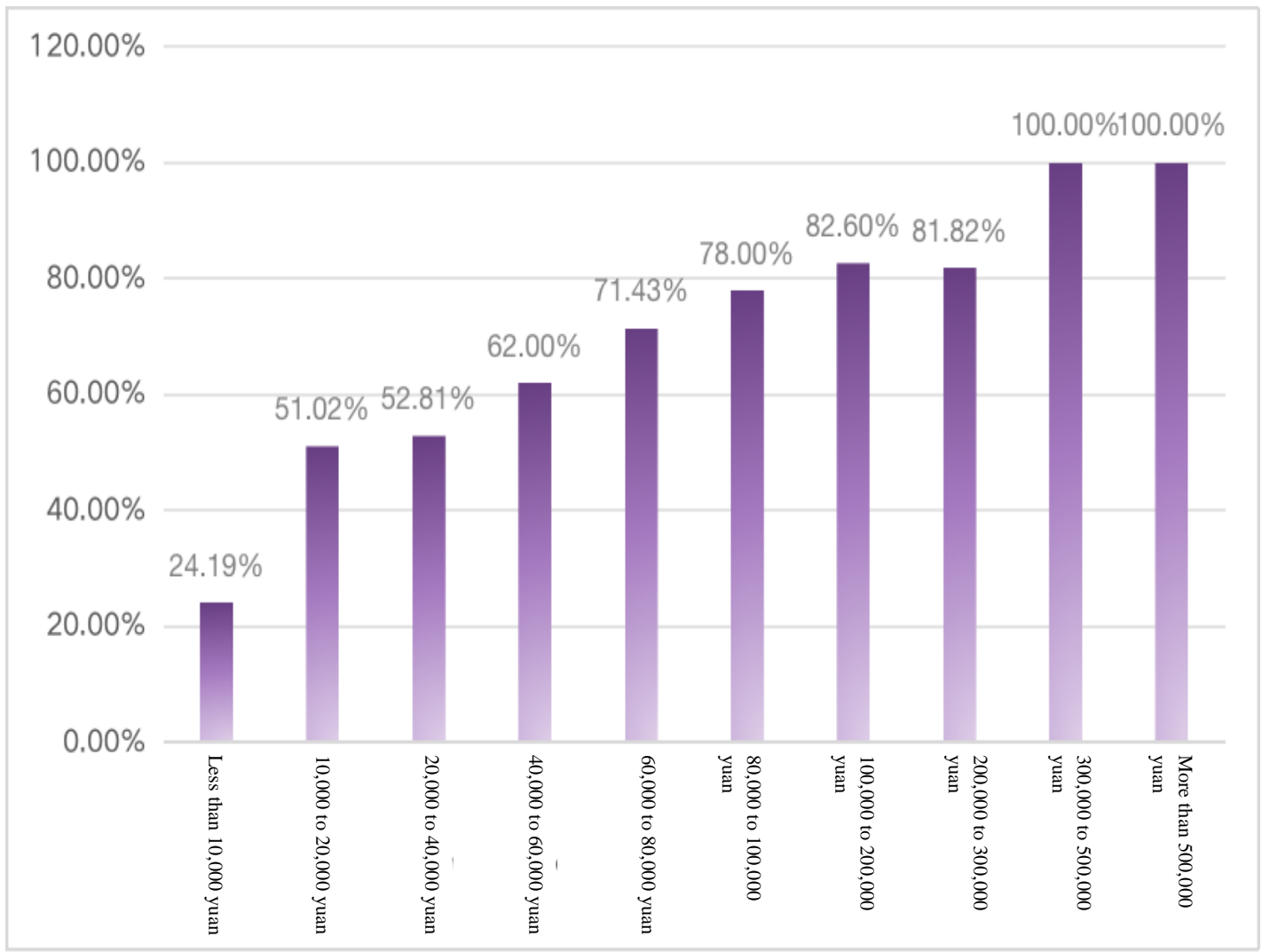

Figure 13

Statistics table of household income and the degree of willingness to purchase agricultural

insurance.

\section{CONCLUSIONS AND SUGGESTIONS}

\subsection{Conclusions}

This paper sorts out and analyzes the data from three perspectives: the economic and social conditions of Yunnan Province, the development of agricultural insurance in Yunnan Province, and the purchase intention and cognition of farmers. The conclusion is divided into two parts for discussion.

From the perspective of agricultural production and agricultural insurance in Yunnan Province:

Firstly, the situation of agricultural production in Yunnan Province is complex, and the agricultural risk is relatively high. There are roughly three types of climate in Yunnan Province, and there are more mountainous areas and inconvenient transportation, bringing higher risk characteristics to agricultural production activities. Analyzing the situation of natural disasters in recent years, the frequency of natural disasters in Yunnan Province is high, and economic losses are relatively serious, further aggravating the risk of agricultural production activities. Therefore, agricultural insurance is of irreplaceable importance for protecting farmers' income and spreading agricultural risks.

Secondly, the guarantee degree of agricultural insurance in Yunnan Province is low and the coverage is narrow. Compared with the good momentum of agricultural development in Yunnan Province, the guarantee degree and coverage of agricultural insurance is far from insufficient, whether it is from the analysis of objective data, the comparison of the development of agricultural insurance across the country, or the data analysis in recent years, the growth momentum of agricultural insurance is weak and lingering, and it is imperative to deepen the coverage and guarantee degree of agricultural insurance.

Thirdly, agricultural insurance itself is a kind of "contract" method that is promised in advance. It can't be purchased after the event, and it is also difficult to predict the future losses and returns of agricultural production. However, many farmers realize the importance of agricultural insurance only after the occurrence of agricultural disasters, 
or under the circumstances of heavy agricultural economic losses.

From the perspective of farmers' cognition and purchase intention:

Firstly, the impact of path dependence on farmers' cognition and behaviour: According to the survey, the surveyed farmers are generally older and less educated. Their cognition, understanding and acceptance of agricultural insurance are low originally. Under the influence of educational level, location, and traditional concepts, it is difficult for them to jump outside the scope of cognition to accept unknown or new things.

Secondly, the incidence of agricultural risks among farmers, insurance companies or even farmers and the makers of agricultural insurance is itself a state of unequal information. In the process of the interviewees' participation, the most prominent option is that they do not trust or understand agricultural insurance at all. Some places even don't offer such services, let alone for farmers to purchase the insurance. Among them, the more prominent is that farmers believe that other methods can be used to resolve agricultural risks. After in-depth interviews and inquiries, this method of resolution often relies on "help from relatives and friends" and "government relief", but neither of these two methods can get the most "economic compensation". In such a situation where the information is not equal, it is not difficult to understand why they make an adverse choice. In fact, if one has a thorough understanding of agricultural insurance, one will find that most of them do not require costly defrayment. However, the income of agriculture itself is not completely stable. It is inevitable that some people will have a "fluke mind" and think that they are not necessarily affected by natural disasters to affect production and income.

Thirdly, the willingness of farmers to buy is not high, and the degree of connection between agricultural insurance and farmers is low. The survey shows that only over half of the farmers are willing to buy agricultural insurance, and the willingness to buy is not high. Apart from factors such as "don't understand and don't believe in agricultural insurance", it is also an objective fact that the degree of agricultural insurance coverage is not high. In addition, the types of agricultural insurance required by farmers have not been fully provided, and the types of agricultural insurance have not been fully connected with market demand.
Fourthly, the impact of household income on risk perception: According to the analysis of the questionnaire, the higher the household income, the stronger the willingness of farmers to buy agricultural insurance. According to the actual situation, high-income farmers are often not engaged in a single agricultural production activity, or their own production scale is large, high income is accompanied by high risks, and once they encounter risks, the losses are also huge. They are more willing to buy insurance to increase the "safety" of their production activities. On the other hand, the high-income group also means a broader experience and deepening of cognitive abilities, and it is easier to understand and accept agricultural insurance, and to be able to "weight the advantages and disadvantages".

\subsection{Suggestions}

The government and insurance companies need to adopt a variety of methods and paradigms to deepen and broaden the coverage of agricultural insurance, and help farmers to effectively prevent agricultural risks. Given the good momentum of development of the agricultural industry, the risk guarantee of agricultural production activities needs to keep pace with the times. The services and types of agricultural insurance should be well connected with the actual needs of farmers, and should be covered in areas with higher levels of demand and areas with higher agricultural risks, so as to meet the farmers' needs of different types of agricultural insurance and make Yunnan's agricultural insurance market present diversified and humanized characteristics.

Farmers' willingness to purchase agricultural insurance is highly dependent on their cognition, and low-income groups should be more protected by agricultural insurance. The popularization and promotion of agricultural insurance knowledge can be popularized in a variety of new channels, closely relying on the leadership of the government and cooperatives and combining the power of the Internet and social media, allowing farmers to learn and understand the knowledge of agricultural insurance and the guarantee function of agricultural insurance in different ways, reducing the phenomenon of "inequity between information", improving adverse selection of agricultural risky production, increasing the willingness to purchase agricultural insurance, and promoting the development of the agricultural insurance market. 
Efforts should be made to Strengthen the interaction among agricultural insurance companies, the government, and new business entities (cooperatives, leading enterprises, etc.), and form a "linkage mechanism" to take the lead and drive small agricultural farmers to purchase agricultural insurance. For cooperatives or large enterprises, a "principal-agent" method can be used to purchase agricultural insurance on behalf of small farmers (refer to tobacco companies), which not only protects the interests of small farmers, but also concentrates efforts to purchase suitable agricultural insurance products, dispersing the risk of agricultural production, and at the same time enhancing the interaction among the three, facilitating the exchange and sharing of information, and enhancing work efficiency.

\section{AUTHORS' CONTRIBUTIONS}

Yu Song is responsible for article writing and editing, Renbo Jiang analysed data and editing, Xin Peng analysed data and image and editing, Yerong Li contributed trevising and editing.

\section{REFERENCES}

[1] Lu Xianxiang. Zhu Qiaoling. Neoinstitutional Economics [M]. Peking University Press, 2012. (in Chinese)

[2] Ahsan, Ali and Kurian, Corp insurance reconsidered [J]. Amer.J.Agr.Econ. 86(5), (1982): 1179-1195.

[3] Knight T.O. K.H. Coble, 1997, A Survey of Multiple Peril Crop Insurance Literature Since 1980, Review of Agricultural Economics, 19:128-156.

[4] Tuo Guozhu. China Agricultural Insurance Research [M]. China Agriculture Press, 2019. (in Chinese)

[5] Chao Nana, Yang Ruihua. Difference Analysis on Cotton Growers' Willingness and Behavior of Agricultural Insurance Participation in Xinjiang $[\mathrm{J}]$. Journal of Beijing University of Aeronautics and Astronautics (Social Sciences Edition), 2019, 32(03):87-92+123. (in Chinese)

[6] Jiang Hua. Deepening the Path and Thinking of Poverty Relief with Insurance in Henan Province - Based on the Poverty Relief Practice of Zhongyuan Agricultural Insurance
[J]. China Insurance, 2019(01):19-24. (in Chinese)

[7] Mhring N, T D alhaus, Enjolras G, et al. Crop insurance and pesticide use in European agriculture [J]. Agricultural Systems, 2020, 184.

[8] Tuo Guozhu, Zhu Junsheng. Revenue Insurance: An Important Means to Perfect the Farm Produce Price Formation Mechanism Reform [J]. Insurance Studies, 2016(06):3-11. (in Chinese)

[9] Yao Fei, Wu Yingzhen. Agricultural Insurance Analysis Under the Complete Information Static Game - Taking Gansu Province as an Example [J]. Chinese Agricultural Science Bulletin, 2015, 31(13):279. (in Chinese)

[10] Bai Zhengjie. Analysis of the Impact of Farmers' Income on Agricultural Insurance Demand - Based on the Survey Data of 1028 peasant households in the Loess Plateau Region of Gansu Province [J]. Gansu Social Sciences, 2012(04):225-228. (in Chinese) 